Original Article

\title{
Effects of 12-week exercise training on osteocalcin, high-sensitivity C-reactive protein concentrations, and insulin resistance in elderly females with osteoporosis
}

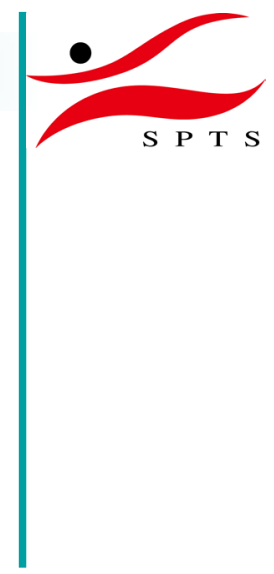

\author{
Nayoung Ahn, $\mathrm{PhD}^{1)}$, KiJin Kim, $\mathrm{PhD}^{1)^{*}}$ \\ 1) Department of Physical Education, College of Physical Education, Keimyung University: \\ 2800 Dalgubeoldaero, Dalseo-gu, Daegu 704-701, Republic of Korea
}

\begin{abstract}
Purpose] This study examined the effects of exercise training on bone metabolism markers, inflammatory markers, and physical fitness in patients with osteoporosis from an osteoporosis-related immunological perspective. [Subjects and Methods] Twenty-nine elderly female subjects (age, $74.2 \pm 3.2$ years) were classified into normal, osteopenia, and osteoporosis groups based on the T-score measured using dual-energy X-ray absorptiometry. The exercise was performed voluntarily by the patients for 1 hour per day, three times per week, for 12 weeks. [Results] The differences between bone mineral content, bone mineral density, and osteocalcin concentrations increased significantly in the osteoporosis group after 12 weeks of exercise and were significantly higher than those in the normal and osteopenia groups. However, the homeostatic model assessment of insulin resistance score decreased significantly in the osteoporosis group after 12 weeks of exercise. High-sensitivity C-reactive protein concentrations tended to decrease in all groups after 12 weeks of exercise and showed an inverse correlation with osteocalcin concentration; however, no statistical significance was observed. [Conclusion] Our findings suggest that an exercise program in patients with osteopenia and osteoporosis effectively reduces the risk of osteoporotic fracture and related diseases since it improves bone density and physical fitness and reduces inflammatory marker levels.

Key words: Osteoporosis, Exercise, Osteocalcin
\end{abstract}

(This article was submitted Feb. 15, 2016, and was accepted May 7, 2016)

\section{INTRODUCTION}

Osteoporosis occurs when bone strength deteriorates due to decreases in bone mineral content (BMC) and bone mineral density (BMD), the most basic markers of bone metabolism, as well as changes in bone microarchitecture, all of which occur with aging ${ }^{1)}$. In particular, osteoporotic fractures occur most frequently in the spine, hip joints, and wrist and can restrict an individual's activity in old age as well as increase psychological and economic losses and mortality rates ${ }^{2}$. A $10 \%$ decrease in BMD results in a fracture risk that is increased by 1.6-2.6 times ${ }^{3,4)}$, and BMC is regulated through a complex process that involves a variety of factors such as ethnicity, genetic factors, hormones, calcium intake, and exercise in the balanced process of bone formation and bone resorption ${ }^{5}$.

Bone structure is reconstructed by osteoblast and osteoclast remodeling on a regular basis. Pro-inflammatory cytokines such as interleukins, tumor necrosis factor- $\alpha$, and C-reactive protein (CRP), which increase in a systemic inflammatory state, activate bone resorption, thereby accelerating bone density loss and fractures ${ }^{6}$. Osteoporotic fractures are associated with chronic inflammatory diseases, in which bone density is reportedly decreased ${ }^{7}$. Interest has recently increased in osteoim-

*Corresponding author. Kijin Kim (E-mail: kjk744@kmu.ac.kr)

(C2016 The Society of Physical Therapy Science. Published by IPEC Inc.

This is an open-access article distributed under the terms of the Creative Commons Attribution Non-Commercial No Derivatives (by-nc-nd) License $<$ http://creativecommons.org/licenses/by-nc-nd/4.0/>. 
munology, the study of the cross-talk of immune factors or interactions between the immune system and bone tissue, and the components of the immune system may have complex effects on bone that lead to osteoporosis ${ }^{8,9)}$. Age-related losses in bone BMD are seen more commonly in females than in males ${ }^{10,11)}$.

Therefore, this study examined the effect of exercise training on bone metabolism markers, inflammatory markers, and physical fitness in patients with osteoporosis from an osteoporosis-related immunological perspective.

\section{SUBJECTS AND METHODS}

Twenty-nine elderly female subjects (age, $74.2 \pm 3.2$ years; height, $150.7 \pm 1.4 \mathrm{~cm}$; body weight, $53.5 \pm 1.9 \mathrm{~kg}$; body mass index, $24.9 \pm 1.4 \mathrm{~kg} / \mathrm{m}^{2}$; \% fat, $25.7 \pm 0.9$; systolic blood pressure, $123.7 \pm 4.3 \mathrm{mmHg}$; diastolic blood pressure, $76.3 \pm$ $2.4 \mathrm{mmHg}$; BMD, $0.9 \pm 0.1 \mathrm{~g} / \mathrm{cm}^{2}$; BMC, $46.9 \pm 3.7 \mathrm{~g}$ ) were included. Voluntary exercise (resistance elastic band exercise, yoga, senior dance) was performed by the subjects for 1 hour per day three times per week for 12 weeks. The patients underwent BMD measurements at the anteroposterior parts of the lumbar (L2-L4) spine by using a QDR-4500 DEXA bone densitometer (Hologic Inc., Waltham, MA, USA) and were classified into normal (T-score $\geq-1 ; n=6$ ), osteopenia (T-score= -1.0 to $-2.5 ; \mathrm{n}=13$ ), and osteoporosis ( $\mathrm{T}$-score $\leq-2.5 ; \mathrm{n}=12$ ) groups based on T-score. The patients were not informed of their T-score before the exercise program and were advised to refrain from taking medicine whenever possible. Written informed consent was obtained from each subject. The study protocol complied with the Declaration of Helsinki.

Comprehensive physical activity is recommended for older adults that consists of aerobic, muscle-strengthening, flexibility, and balance activities that promote health ${ }^{12}$. Yoga, resistance elastic band exercise, and senior dance were performed voluntarily for 12 weeks. Asana yoga was performed. The resistance elastic band exercise consisted of sitting and standing movements. The senior dance with a focus on aerobic exercise was performed to music. To control exercise intensity, the heart rate was regularly measured and was maintained at a moderate rate in the range of $120-130$ beats $/ \mathrm{min}$ and at a rated perceived exertion (RPE) of 12-14. Warm-up and cool-down were performed at an RPE of 9-10 for 5-10 minutes each.

Lower-extremity endurance was tested by the chair squat on a chair $46 \mathrm{~cm}$ tall without armrests; the number of repetitions in $30 \mathrm{~s}$ was recorded ( $\mathrm{sit} \& \mathrm{up}$, times $/ 30 \mathrm{~s}$ ). The timed up-and-go test was used to evaluate dynamic balance ability (sec/3 m). The number of steps in the same spot was measured for $2 \mathrm{~min}$ to measure cardiorespiratory function. Static balance ability was evaluated by the one-leg stance test (right leg), in which the participant stood on one foot with their eyes open.

A 5-ml blood sample collected from the patients was centrifuged at 3,000 rpm for 20 minutes to separate the serum, and high-sensitivity C-reactive protein (hs-CRP) concentrations were analyzed using latex agglutination turbidimetry on a BN analyzer (Hitachi 77600-110, 7170; Hitachi Ltd., Tokyo, Japan). Glucose concentrations were measured using the enzymatic method on an automatic analyzer (Auto-analyzer Hitachi 7150, Hitachi Ltd.), while serum insulin concentrations were measured using immunoradiometric assays. HOMA-IR was calculated using the following formula: fasting blood insulin concentration $(\mu \mathrm{U} / \mathrm{ml}) \times$ fasting blood glucose concentration $(\mathrm{mmol} / \mathrm{l}) / 22.5$ based on the homeostasis model ${ }^{13)}$. Osteocalcin concentration was analyzed by an enzyme-linked immunosorbent assay (Biotek Instrument Inc., Windoski, VT, USA) using a NovoClacin kit (Metra Biosystem Inc., Mountain view, CA, USA).

For all data, the mean and standard deviation for each group were calculated using SPSS version 17.0 (SPSS Inc., Chicago, IL, USA). Inter-group differences in bone metabolism markers before and after exercise were analyzed using one-way analysis of variance, and glucose metabolism markers, inflammatory markers, and physical fitness assessment variables before versus after exercise were analyzed using a paired t-test. The correlation of each variable was assessed using Pearson's correlation analysis. Statistical significance was set at $\mathrm{p}<0.05$.

\section{RESULTS}

Regarding the changes in bone metabolism markers after 12 weeks of exercise, the differences in BMC, BMD, and serum osteocalcin concentration increased significantly in the osteoporosis group after 12 weeks of exercise and were significantly higher than those in the normal and osteopenia groups $(\mathrm{p}<0.05)$. In addition, T-score differences were increased in the osteopenia and osteoporosis groups (Fig. 1). Glucose and insulin concentrations were decreased in all groups; in particular, mean insulin concentration significantly decreased in the osteoporosis group $(\mathrm{p}<0.01)$, exhibiting a significant decrease in HOMA-IR ( $<$ 0.01) (Fig. 2). With regard to the changes in inflammatory markers after the 12-week exercise program, hs-CRP concentration tended to decrease in all groups (Fig. 3). Regarding the correlations between bone-related markers, insulin resistance, and pro-inflammatory markers after the 12-week exercise program, hs-CRP was negatively correlated with osteocalcin concentration and HOMA-IR in all groups, but the differences were not significant. With regard to changes in physical fitness after the 12-week exercise program, muscular endurance of the lower extremity and balance ability improved in the osteopenia and osteoporosis groups (Fig. 4). The hs-CRP concentrations tended to decrease in all groups after the 12 weeks of exercise and were negatively correlated with osteocalcin concentration; however, no significant differences were observed (Table 1). 

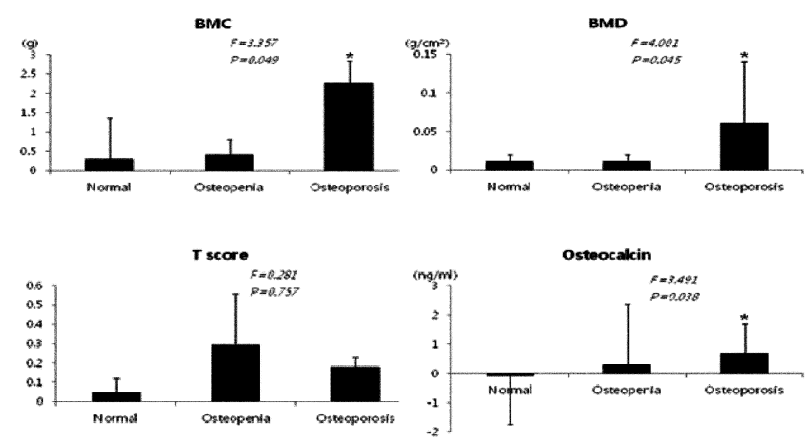

Fig. 1. Comparison of the differences in BMC, BMD, T-score, and osteocalcin concentrations before versus after exercise

BMC: bone mineral content; BMD: bone mineral density; T-score: normal $\geq-1$, osteopenia $=-1.0$ to -2.5 , osteoporosis $\leq-2.5 ;{ }^{*} \mathrm{p}<0.05$, significantly different from the normal group

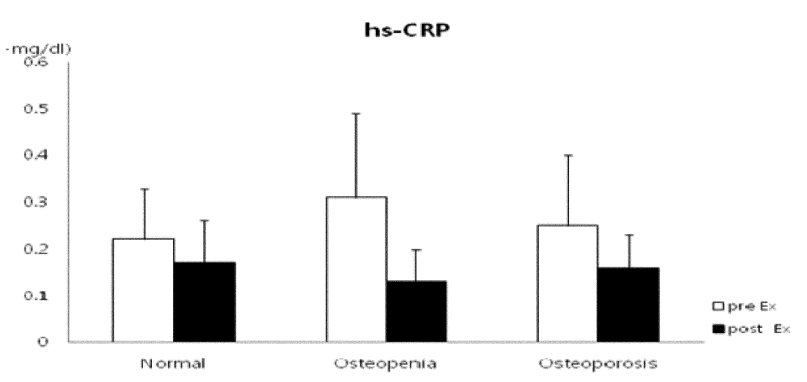

Fig. 3. Change in hs-CRP concentration after the 12-week exercise training in elderly females

hs-CRP: high-sensitivity C-reactive protein

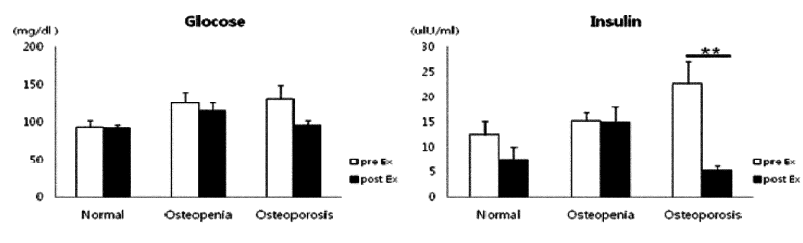

HOMA-IR

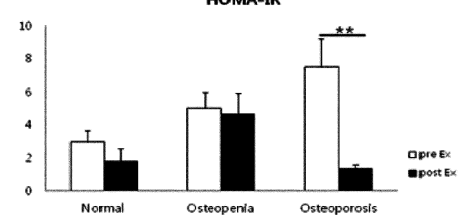

Fig. 2. Change in glucose concentration, insulin concentration, and HOMA-IR after 12-week exercise training in elderly females

HOMA-IR: homeostatic model assessment of insulin resistance Values are mean $\pm \mathrm{SD} ; * * \mathrm{p}<0.01$, pre- vs. post-exercise
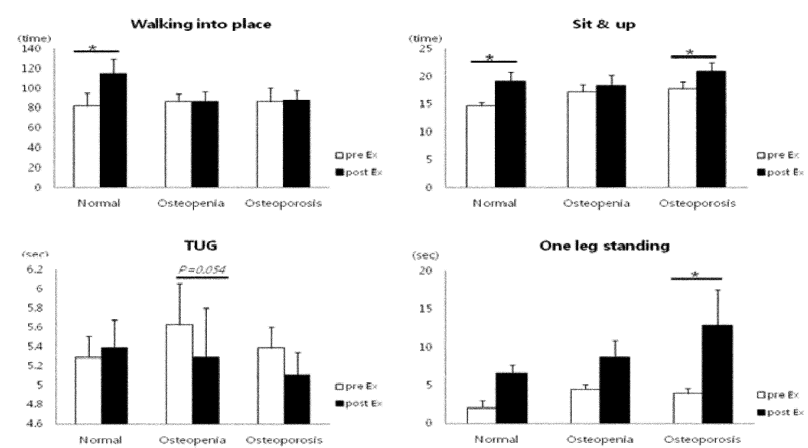

Fig. 4. Changes in physical fitness variables after 12-week exercise training in elderly females

TUG: timed up-and-go test. Values are mean $\pm \mathrm{SD} ;{ }^{*} \mathrm{p}<0.05$, prevs. post-exercise

Table 1. Correlation among hs-CRP, osteocalcin, and HOMA-IR after 12-week exercise training

\begin{tabular}{lcccccc}
\hline & \multicolumn{2}{c}{ Normal } & \multicolumn{2}{c}{ Osteopenia } & \multicolumn{2}{c}{ Osteoporosis } \\
\hline & $\begin{array}{c}\text { Osteocalcin } \\
(\mathrm{ng} / \mathrm{ml})\end{array}$ & HOMA-IR & $\begin{array}{c}\text { Osteocalcin } \\
(\mathrm{ng} / \mathrm{ml})\end{array}$ & HOMA-IR & $\begin{array}{c}\text { Osteocalcin } \\
(\mathrm{ng} / \mathrm{ml})\end{array}$ & HOMA-IR \\
\hline hs-CRP $(\mathrm{mg} / \mathrm{dl})$ & -0.412 & -0.362 & 0.022 & -0.161 & -0.044 & -0.209 \\
Osteocalcin $(\mathrm{ng} / \mathrm{ml})$ & & -0.316 & & 0.094 & & -0.055 \\
\hline
\end{tabular}

hs-CRP: high-sensitivity C-reactive protein; HOMA-IR:homeostatic model assessment of insulin resistance

\section{DISCUSSION}

Exercise performance reportedly has great effects on bone formation ${ }^{14,15)}$ and BMD improvement ${ }^{16)}$. In previous studies on the correlations between exercise and osteocalcin concentration, when mature male mice were subjected to a 6-week lowand high-intensity ladder exercise, the results showed that serum osteocalcin concentration significantly increased in the two groups compared to the control group, whereas BMD significantly increased in the high-intensity exercise group alone ${ }^{17)}$. In addition, in vitro and in vivo studies have shown that exercise as mechanical stimulation inhibits osteoclast formation and increases the OPG/RANKL ratio ${ }^{18)}$. In this study, performing 12-week exercise improved BMC, BMD, and osteocalcin concentration, implying improvement in maximum bone mass and bone density. These findings are similar to the results of a study demonstrating that osteocalcin concentration increased in post-menopausal females with a low BMD who performed underwater exercise for 8 months ${ }^{19}$. 
Hs-CRP, a vascular inflammatory marker, is known to be highly relevant to metabolic diseases and increases in postmenopausal females. Pro-inflammatory cytokine derived from monocytes, macrophages, and adipocytes increase CRP levels; CRP is synthesized in the liver and enters the blood. Therefore, hs-CRP concentration can be decreased by a decrease in body fat due to physical activity ${ }^{20}$. The decrease in muscular strength that may cause a decline in physical fitness in older people was recently suggested to be related to the systemic and chronic inflammatory state ${ }^{21)}$.

In line with previous reports that a negative correlation exists between osteocalcin and hs-CRP concentrations ${ }^{22,23)}$, the results of this study revealed that hs-CRP concentration decreased after 12 weeks of exercise and that there was a negative correlation between hs-CRP and osteocalcin concentrations. In addition, increased insulin resistance is mostly accompanied by the accumulation of body fat and the abnormal state of metabolic variables; thus, it is highly related to increased risks of obesity, atherosclerosis, and cardiovascular disease ${ }^{24)}$. Therefore, in this study, osteocalcin concentration was inversely correlated with HOMA-IR in osteoporosis group after exercise, but no statistical significance.

Exercise improves muscular strength and balance ability in older people. When resistance exercise was performed in older females with a low bone mass, a 57\% decrease in the risk of fracture was found, while agility exercise and stretching resulted in a $48 \%$ reduction and $20 \%$ decrease in the risk of fracture, respectively ${ }^{25)}$. In conclusion, after the 12-week exercise training program, the elderly females with osteopenia and osteoporosis demonstrated improvements in cardiopulmonary function, muscular endurance of the lower extremities, and balance ability. Therefore, although this study is limited by the lack of a control group and small sample size, examining the correlation between the bone metabolic markers and the stimulatory and inhibitory activities that induce bone turnover and the inflammatory biomarkers after exercise training for patients with osteopenia and osteoporosis is very important in decreasing the risk of osteoporotic fractures and related diseases by enhancing bone density and physical fitness as well as by decreasing the inflammatory marker concentrations.

\section{REFERENCES}

1) Kim TH, Lee HH, Chung SH: A difference of bone fracture rate and frequency to have determined in diagnosis standards. Osteoporosis, 2010, 8: 266-270.

2) Peeters G, van Schoor NM, Lips P: Fall risk: the clinical relevance of falls and how to integrate fall risk with fracture risk. Best Pract Res Clin Rheumatol, 2009, 23: 797-804. [Medline] [CrossRef]

3) Marshall D, Johnell O, Wedel H: Meta-analysis of how well measures of bone mineral density predict occurrence of osteoporotic fractures. BMJ, 1996, 312: 1254-1259. [Medline] [CrossRef]

4) World Health Organization: WHO scientific group on the assessment of osteoporosis at primary health care level: summary meeting report. Belgium WHO, $2004,5-7$.

5) Kim SR, Ha YC, Kim JR, et al.: Incidence of hip fractures in Jeju Island, South Korea: a prospective study (2002-2006). Clin Orthop Surg, 2010, 2: 64-68. [Medline] [CrossRef]

6) Salamone LM, Whiteside T, Friberg D, et al.: Cytokine production and bone mineral density at the lumbar spine and femoral neck in premenopausal women. Calcif Tissue Int, 1998, 63: 466-470. [Medline] [CrossRef]

7) Cleland SJ, Petrie JR, Small M, et al.: Insulin action is associated with endothelial function in hypertension and type 2 diabetes. Hypertension, 2000, 35: 507-511. [Medline] [CrossRef]

8) Arron JR, Choi Y: Bone versus immune system. Nature, 2000, 408: 535-536. [Medline] [CrossRef]

9) Rauner M, Sipos W, Thiele S, et al.: Advances in osteoimmunology: pathophysiologic concepts and treatment opportunities. Int Arch Allergy Immunol, 2013, 160: 114-125. [Medline] [CrossRef]

10) Daly RM, Rosengren BE, Alwis G, et al.: Gender specific age-related changes in bone density, muscle strength and functional performance in the elderly: a-10 year prospective population-based study. BMC Geriatr, 2013, 13: 71 [CrossRef]. [Medline]

11) Macdonald HM, Nishiyama KK, Kang J, et al.: Age-related patterns of trabecular and cortical bone loss differ between sexes and skeletal sites: a populationbased HR-pQCT study. J Bone Miner Res, 2011, 26: 50-62. [Medline] [CrossRef]

12) Nelson ME, Rejeski WJ, Blair SN, et al. American College of Sports Medicine American Heart Association: Physical activity and public health in older adults: recommendation from the American College of Sports Medicine and the American Heart Association. Circulation, 2007, 116: 1094-1105. [Medline] [CrossRef]

13) Matthews DR, Hosker JP, Rudenski AS, et al.: Homeostasis model assessment: insulin resistance and beta-cell function from fasting plasma glucose and insulin concentrations in man. Diabetologia, 1985, 28: 412-419. [Medline] [CrossRef]

14) Banfi G, Lombardi G, Colombini A, et al.: Bone metabolism markers in sports medicine. Sports Med, 2010, 40: 697-714. [Medline] [CrossRef]

15) Smith MZ, Goettsch BM, Van Ramshorst RD, et al.: Resistance training and bone mineral density during growth. Int J Sports Med, 2008, 29: 316-321. [Medline] [CrossRef]

16) Taaffe DR, Marcus R: The muscle strength and bone density relationship in young women: dependence on exercise status. J Sports Med Phys Fitness, 2004, 44: 98-103. [Medline]

17) Delmas PD, Stenner D, Wahner HW, et al.: Increase in serum bone gamma-carboxyglutamic acid protein with aging in women. Implications for the mechanism of age-related bone loss. J Clin Invest, 1983, 71: 1316-1321. [Medline] [CrossRef]

18) Saunders MM, Taylor AF, Du C, et al.: Mechanical stimulation effects on functional end effectors in osteoblastic MG-63 cells. J Biomech, $2006,39:$ 1419-1427. [Medline] [CrossRef]

19) Pernambuco CS, Borba-Pinheiro CJ, Vale RG, et al.: Functional autonomy, bone mineral density (BMD) and serum osteocalcin levels in older female participants of an aquatic exercise program (AAG). Arch Gerontol Geriatr, 2013, 56: 466-471. [Medline] [CrossRef]

20) Jialal I, Devaraj S: Inflammation and atherosclerosis: the value of the high-sensitivity C-reactive protein assay as a risk marker. Am J Clin Pathol, 2001, 116: 
S108-S115. [Medline]

21) Visser M, Pahor M, Taaffe DR, et al.: Relationship of interleukin- 6 and tumor necrosis factor-alpha with muscle mass and muscle strength in elderly men and women: the Health ABC Study. The Journals of Gerontology, Series A. Biol Sci, 2002, 57: M326-M332.

22) Kanazawa I, Yamaguchi T, Yamamoto M, et al.: Serum osteocalcin level is associated with glucose metabolism and atherosclerosis parameters in type 2 diabetes mellitus. J Clin Endocrinol Metab, 2009, 94: 45-49. [Medline] [CrossRef]

23) Pittas AG, Harris SS, Eliades M, et al.: Association between serum osteocalcin and markers of metabolic phenotype. J Clin Endocrinol Metab, 2009, 94 : 827-832. [Medline] [CrossRef]

24) Kanazawa I, Yamaguchi T, Tada Y, et al.: Serum osteocalcin level is positively associated with insulin sensitivity and secretion in patients with type 2 diabetes. Bone, 2011, 48: 720-725. [Medline] [CrossRef]

25) Liu-Ambrose T, Khan KM, Eng JJ, et al.: Resistance and agility training reduce fall risk in women aged 75 to 85 with low bone mass: a 6-month randomized, controlled trial. J Am Geriatr Soc, 2004, 52: 657-665. [Medline] [CrossRef] 